\title{
SONIC BOOM ASSESSMENT FOR THE CREW EXPLORATION VEHICLE
}

\author{
Marissa Herron ${ }^{1}$ \\ NASA/Johnson Space Center, Houston, TX USA
}

The Constellation Environmental Impact Statement (Cx EIS) requires that an assessment be performed on the environmental impact of sonic booms during the reentry of the Crew Exploration Vehicle (CEV). This included an analysis of current planned vehicle trajectories for the Crew Module (CM) and the Service Module (SM) debris and the determination of the potential impact to the overflown environment.

\section{Sonic Boom Overview}

Sonic booms result from supersonic vehicles that create a change in pressure which then propagates to the ground. Pressure signatures show an "N-wave" formation at ground impact of the shock waves as in Figure $1 \mathrm{~N}$-wave, PCBoom4. This is characterized by a sudden increase in pressure at the nose of the vehicle followed by a linear decrease in pressure until the tail is reached at which point the pressure returns to normal. The sudden pressure changes at the nose and tail of the vehicle are each audible on the ground. It is the audible portion of the N-wave that is referred to as "sonic boom."

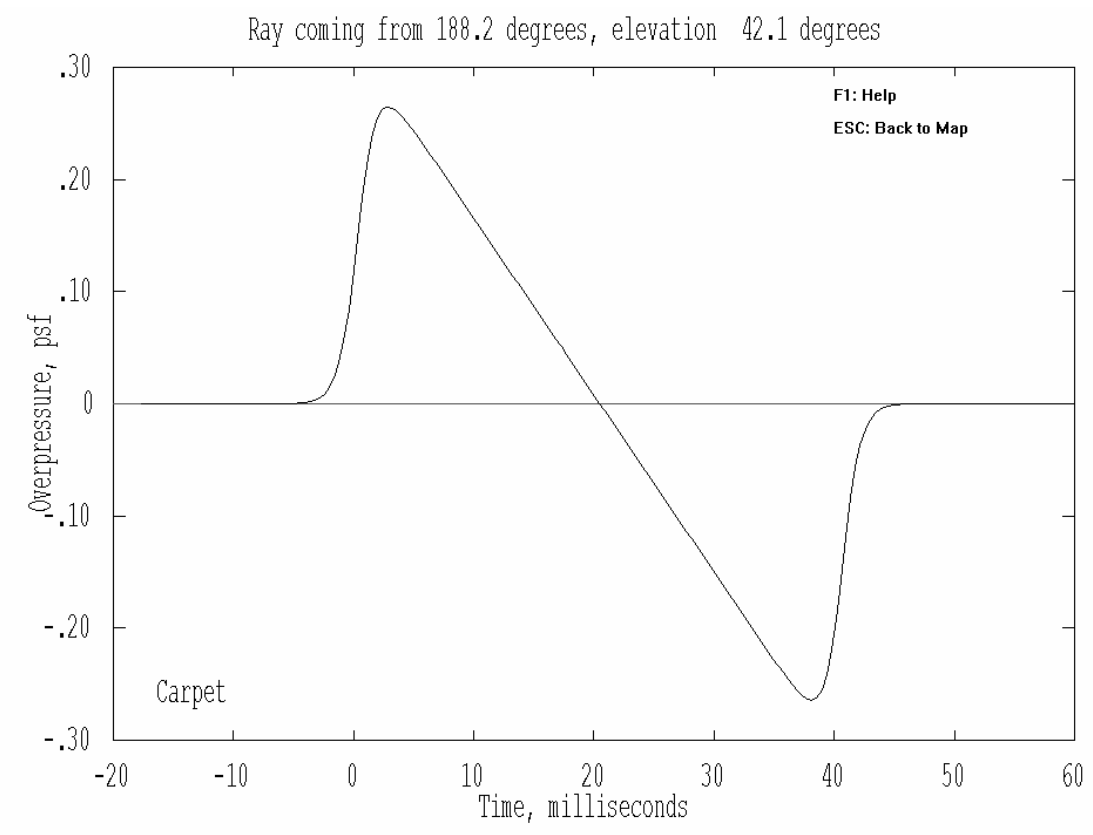

Figure 1 N-wave, PCBoom $^{8}$

As the supersonic vehicle travels, it creates a "boom carpet" which consists of N-waves plotted along the ground path of the vehicle. Figure 2 Sonic Boom Wave and Ray Fields depicts a shock cone (or Mach cone) generated, over a period of time, at the nose of the vehicle (in aircraft fixed-coordinates). The intersection of this shock cone with the ground results in a hyperbolic line called an "isolabe." The isolabe can be considered the

\footnotetext{
${ }^{1}$ Aerospace Engineer, Descent Analysis Group, Flight Design and Dynamics Division, Mail Code DM42, 2101 NASA Parkway, Houston, TX 77058, USA
} 
leading edge of the boom carpet. The ground location of each is dependent upon the Mach number which inversely influences the angle of the shock cone. In other words, higher Mach numbers will produce smaller Mach cone angles resulting in larger distances between the vehicles and the isolabe. For every 1,000 feet of altitude, the width of the boom carpet is about one mile ${ }^{1}$. The magnitude of a sonic boom is greatest directly under the vehicle and decreases as the edges of the boom carpet are approached. Note that the strength and shape of the shock waves (i.e. N-wave) and the resultant boom carpet are dependent upon the distance between the shock waves and the vehicle, atmospheric conditions, and vehicle maneuvers.

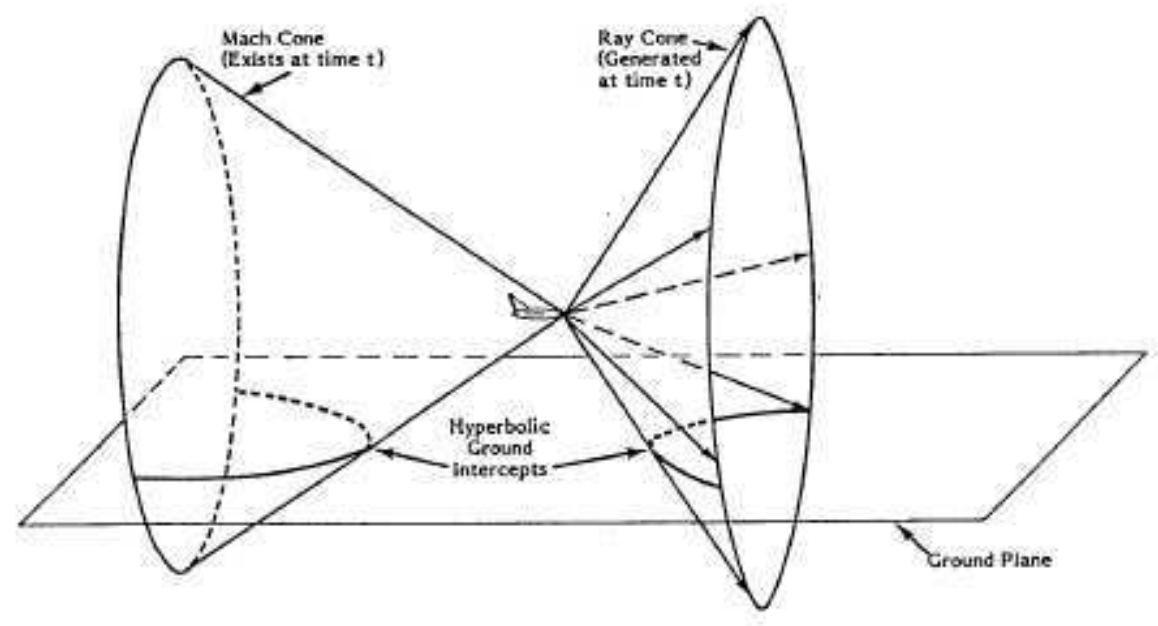

Figure 2 Sonic Boom Wave and Ray Fields ${ }^{12}$

In particular, vehicle maneuvers and accelerations can create focusing. Referring again to Figure 2, consider a ray cone extending from the vehicle at a point in time (in atmosphere-fixed coordinates). These rays travel ahead of the vehicle until they intersect with the ground and represent the trajectory "along which acoustic energy propagates ${ }^{10}$." This hyperbolic intersection is called an "isopemp." Again the Mach number is inversely related to the cone angle and, thus, the ground location of the isopemp. However, note that a large Mach number will increase the ray cone angle which decreases the distance from the vehicle to the isopemp ${ }^{12}$. Interpreted differently, accelerations will alter the ground location of the isopemps creating a focal zone in which the isopemps cross. Crossing isopemps indicate a "superboom", or an amplified sonic boom, and are characterized by a "U-wave" pressure signature?

The size, shape, and weight of a vehicle affect the magnitude of the sonic boom. For example, a large, blunt vehicle will produce a stronger sonic boom than one that is light and slender. The length of the boom is also dependent upon the ratio of the vehicle's cross sectional area to its length ${ }^{13}$.

Atmospheric conditions can create variations in boom carpets. The magnitude of the sonic boom will decrease with increasing altitude of the vehicle as this requires the boom to travel further through the atmosphere ${ }^{2}$. Temperature and density variations can change the magnitude of the sonic boom and the boom carpet characteristics. Winds have little, 
if any, effect on the magnitude. Instead, they change the size and shape of the boom carpet $^{6}$.

Shock waves of sufficient value can cause damage to structures and wildlife upon ground impact. See Table 1 Sonic Boom Damage Table for a list of potential damage based on overpressure values.

Table 1 Sonic Boom Damage Table ${ }^{5}$

\begin{tabular}{|c|c|c|}
\hline $\begin{array}{l}\text { Sonic Boom } \\
\text { Overpressure } \\
\text { Nominal } \\
\text { kPa (psf) }\end{array}$ & Type of Damage & Item Affected \\
\hline \multirow{6}{*}{$\begin{array}{l}0.02-0.10(0.5 \\
-2) \text { Compares } \\
\text { to piledriver at } \\
\text { construction site }\end{array}$} & Cracks in plaster & $\begin{array}{l}\text { Fine; extension of existing; more in ceilings; over door } \\
\text { frames; between some plaster boards. }\end{array}$ \\
\hline & Cracks in glass & Rarely shattered; either partial or extension of existing. \\
\hline & Damage to roof & $\begin{array}{l}\text { Slippage of existing loose tiles/slates; sometimes new } \\
\text { cracking of old slates at nail hole. }\end{array}$ \\
\hline & Damage to outside walls & Existing cracks in stucco extended. \\
\hline & Bric-a-brac & $\begin{array}{l}\text { Those carefully balanced or on edges can fall; fine glass; } \\
\text { e.g., large goblets can fall and break. }\end{array}$ \\
\hline & Other & Dust falls in chimneys. \\
\hline $\begin{array}{c}0.10-0.20 \\
(2-4) \\
\text { Compares to } \\
\text { cap gun or } \\
\text { firecracker near } \\
\text { ear }\end{array}$ & $\begin{array}{l}\text { Glass, plaster, roofs, } \\
\text { ceilings }\end{array}$ & $\begin{array}{l}\text { Failures show which would have been difficult to } \\
\text { forecast in terms of their existing localized condition. } \\
\text { Nominally in good condition. }\end{array}$ \\
\hline \multirow{5}{*}{$\begin{array}{c}0.20-0.50 \\
(4-10) \\
\text { Compares to } \\
\text { handgun as } \\
\text { heard at } \\
\text { shooter's ear }\end{array}$} & Glass & $\begin{array}{l}\text { Regular failures within a population of well-installed } \\
\text { glass; industrial as well as domestic greenhouses. }\end{array}$ \\
\hline & Plaster & $\begin{array}{l}\text { Partial ceiling collapse of good plaster; complete } \\
\text { collapse of very new, incompletely cured, or very old } \\
\text { plaster. }\end{array}$ \\
\hline & Roofs & $\begin{array}{l}\text { High probability rate of failure in nominally good state, } \\
\text { slurry-wash; some chance of failures in tiles on modern } \\
\text { roofs; light roofs (bungalow) or large area con move } \\
\text { bodily. }\end{array}$ \\
\hline & Walls (out) & Old, free standing, in fairly good condition can collapse. \\
\hline & Walls (in) & Inside ("Party") walls known to move at 10 psf. \\
\hline \multirow{6}{*}{$\begin{array}{l}>0.50(>10) \\
\text { Compares to } \\
\text { fireworks } \\
\text { display from } \\
\text { viewing stand }\end{array}$} & Glass & $\begin{array}{l}\text { Some good glass will fail regularly to sonic booms from } \\
\text { the same direction. Glass with existing faults could } \\
\text { shatter and fly. Large window frames move. }\end{array}$ \\
\hline & Plaster & Most plaster affected \\
\hline & Ceilings & Plaster boards displaced by nail popping \\
\hline & Roofs & $\begin{array}{l}\text { Most slate/slurry roofs affected, some badly; large roofs } \\
\text { having good tile can be affected; some roofs bodily } \\
\text { displaced causing gale-end and will-plate cracks; } \\
\text { domestic chimneys dislodged if not in good condition. }\end{array}$ \\
\hline & Walls & $\begin{array}{l}\text { Internal party walls can move even if carrying fittings } \\
\text { such as hand basins or taps; secondary damage due to } \\
\text { water leakage. }\end{array}$ \\
\hline & Bric-a-brac & $\begin{array}{l}\text { Some nominally secure items can fall; e.g., large } \\
\text { pictures, especially if fixed to party walls. }\end{array}$ \\
\hline
\end{tabular}




\section{Program Background}

The sonic boom analysis was performed using PCBoom $4^{8}$, a program developed by Wyle Laboratories and NASA beginning in the mid-70's. PCBoom4 is based on the Thomas method which was also used in previous Space Shuttle sonic boom assessments. A Space Shuttle model and a blunt body model are included with PCBoom4.

The blunt body model employs Tiegermann's method and was tested against the Stardust reentry on 15 January 2006. The calculated and measured overpressure values were $0.0524 \mathrm{psf}$ and $0.052 \mathrm{psf}$, respectively ${ }^{9}$. An earlier version of the model, PCBoom3, was also used by the NASA/Marshall Space Flight Center (MSFC) for an environmental analysis of the X-33 vehicle. ${ }^{5}$

\section{Results}

Lunar CEV trajectories for a single direct entry and three of four operational sites (OS) skip entry trajectories were completed. The altitude and Mach profiles of the lunar entries are plotted in Figure $3 \mathrm{CEV}$ and Shuttle Altitude and Mach Data. Each of the cases was evaluated with the same reentry mass value of $14,823.2$ pounds ${ }^{1}$. The results are shown in Table 2 Sonic Boom CM Results using PCBoom 4 and plotted together in Figure 9 CM Trajectories of Lunar Cases Tested, GoogleEarth and Figure $10 \mathrm{CM}$ Pressure Contours at Lunar Landing Sites, GoogleEarth. Winds were not considered for the current results, but may be included in future work.

The lunar direct entry to Carson Flats, NV generated the smallest overpressure value of 0.33 psf. The entire boom carpet is shown in Figure 9. The boom carpet contains two separate regions of pressure contours. The maximum area of pressure is located approximately $10.12 \mathrm{~nm}$ before the targeted landing site (see Figure 4 CEV CM Lunar Direct Entry to Carson Flats, NV).

Currently there are four different OS skip entries planned for the CEV. A skip entry involves the vehicle entering, descending to some point at which the altitude begins to rise ("the skip") and reaches a peak altitude where re-entry starts. The benefits of this method are flexibility in range and weather constraints, as well as those imposed by lunar inclination variation.

At the time of this study, only OS 2,3, and 4 trajectories were available. The landing site for OS 2 is the Utah Test Range (UTTR). The maximum overpressure value for this entry was calculated as $0.43 \mathrm{psf}$ occurring approximately $5.75 \mathrm{~nm}$ south-east of the targeted landing site (see Figure 5 CEV CM Utah Test Range Lunar Skip OS2). Notice, from Figure 9, that only the re-entry portion of OS2 was included (trajectory is a shorter length than the others) due to PCBoom4 limitations on the data array size. Maximum overpressure results were not affected by this limitation.

OS 3 and OS 4 each land at Edwards AFB (EDW). The calculated maximum overpressure value for OS 3 matched that of OS 2 with OS 4 producing a slightly smaller value of $0.41 \mathrm{psf}$. The maximum overpressure regions for OS 3 and OS 4 are approximately $6.83 \mathrm{~nm}$ south-west and $18.89 \mathrm{~nm}$ west of the targeted landing site, 
respectively. The pressure contours for these trajectories are shown in Figure 6 CEV CM Edwards AFB Lunar Skip OS3 and Figure 7 CEV CM Edwards AFB Lunar Skip OS4.

As a comparison to the above calculated values, STS-26 measured the space shuttle entry to have a maximum overpressure value of $1.28 \mathrm{psf}^{3}$. An Edwards shuttle trajectory was also run through PCBoom4 which calculated a slightly lower maximum overpressure value of 1 psf (see Figure 8 Shuttle Entry to EDW). The differences between the actual and calculated values are likely due to PCBoom4 variations in the shuttle model (i.e. smaller mass than what was actually flown), the atmospheric model, and the trajectory data.

Table 2 Sonic Boom CM Results using PCBoom4

\begin{tabular}{|l|l|l|}
\hline CEV Trajectory Details & Landing Site & $\begin{array}{l}\text { Maximum Overpressure } \\
\text { (psf) }\end{array}$ \\
\hline Lunar Direct & Carson Flats, NV & 0.33 \\
\hline Lunar Skip Ops Site 1 & \multicolumn{2}{|c|}{ Trajectory Not Available } \\
\hline Lunar Skip Ops Site 2 & Utah Test Range, UT & 0.43 \\
\hline Lunar Skip Ops Site 3 & Edwards AFB, CA & 0.43 \\
\hline Lunar Skip Ops Site 4 & Edwards AFB, CA & 0.41 \\
\hline Abort & \multicolumn{2}{|c|}{ Trajectory Not Available } \\
\hline
\end{tabular}

International Space Station (ISS) and lunar cases were also considered for the SM debris. In the absence of an existing debris catalog, the potential SM debris was bounded by applying a heel, toe, left, and right method which is typically used to create debris footprints. Table 3 Debris Footprint Boundary Parameters lists the details of these parameters. The boundaries were chosen so as to evaluate a conservative representation of ground coverage. In addition to footprint size, two different mass values were considered, $9100 \mathrm{lbs}$ and $100 \mathrm{lbs}$. The larger of the two represents the SM mass prior to breakup and was chosen to simply consider a worst case scenario. The smaller mass value represents a more realistic value of debris mass.

Table 3 Debris Footprint Boundary Parameters

\begin{tabular}{|l|l|l|l|}
\hline $\begin{array}{l}\text { Footprint } \\
\text { Boundary }\end{array}$ & Lift/Drag & $\begin{array}{l}\text { Ballistic } \\
\text { Coefficient (psf) }\end{array}$ & Bank Angle (deg) \\
\hline Heel & 0.15 & 0.5 & 180 \\
\hline Toe & 0 & 123 & - \\
\hline Left & 0.15 & 20 & -60 \\
\hline Right & 0.15 & 20 & 60 \\
\hline
\end{tabular}

Beginning from a break up altitude of $255,200 \mathrm{ft}$, the four debris footprint boundaries were considered for each mass value. The ISS trajectory results are contained in Table 4 Sonic Boom ISS SM Debris Results using PCBoom4. Notice that the larger mass values produce a maximum overpressure similar to that of the CEV CM results. Considering such a large mass value and a slightly higher Mach number than the CM these results are reasonable. For the smaller mass value, the maximum overpressure results decreased by 
an order of magnitude. For trajectory details and pressure contours see Figure 11 through Figure 15.

The lunar case results show a similar pattern to that of the ISS results (see Table 5 Sonic Boom Lunar SM Debris Results using PCBoom4). The maximum overpressure values show a slight increase from the ISS cases, but remain at the same order of magnitude. Details of the altitude and Mach data, for the lunar cases, are presented in Figure 16 Lunar SM Debris Altitude and Mach Data. The pressure contours are shown throughout the remaining figures.

Table 4 Sonic Boom ISS SM Debris Results using PCBoom4

\begin{tabular}{|l|l|l|l|}
\hline Debris Piece & Mass (lbs) & $\begin{array}{l}\text { Maximum } \\
\text { Overpressure (psf) }\end{array}$ & Trajectory Type \\
\hline Toe & 9100 & 0.43 & ISS \\
\hline Heel & 9100 & 0.19 & ISS \\
\hline Left & 9100 & 0.39 & ISS \\
\hline Right & 9100 & 0.39 & ISS \\
\hline Toe & 100 & 0.040 & ISS \\
\hline Heel & 100 & 0.037 & ISS \\
\hline Left & 100 & 0.049 & ISS \\
\hline Right & 100 & 0.049 & ISS \\
\hline
\end{tabular}

Table 5 Sonic Boom Lunar SM Debris Results using PCBoom4

\begin{tabular}{|l|l|l|l|}
\hline Debris Piece & Mass (lbs) & $\begin{array}{l}\text { Maximum } \\
\text { Overpressure (psf) }\end{array}$ & Trajectory Type \\
\hline Toe & 9100 & 0.43 & Lunar \\
\hline Heel & 9100 & 0.27 & Lunar \\
\hline Left & 9100 & 0.51 & Lunar \\
\hline Right & 9100 & 0.51 & Lunar \\
\hline Toe & 100 & 0.054 & Lunar \\
\hline Heel & 100 & 0.049 & Lunar \\
\hline Left & 100 & 0.074 & Lunar \\
\hline Right & 100 & 0.074 & Lunar \\
\hline
\end{tabular}

Note that the overpressure values presented are specific to an individual piece of debris. The possibility of overlapping sonic booms is not considered. As previously discussed, overlapping isopemps from a single aircraft indicate focusing and result in a superboom. However, there exists little research into the result of overlapping sonic booms created from separate aircraft, which would be analogous to separate debris pieces. At least one known study was completed that involved multiple aircraft flying in close formation so as to intentionally create overlapping sonic booms. The tests found that the sonic booms remained separate ${ }^{6}$. The amount of falling debris will obviously increase the possibility of overlapping sonic booms, however, the current results of individual debris pieces are so low that even if multiple booms coincided it is unlikely that the result would be cause for concern. 


\section{Conclusion}

The maximum overpressure for each of the CM and SM debris trajectories remain well below the Space Shuttle maximum overpressure of 1.28 psf. Recall that Table 1 begins at $0.5 \mathrm{psf}$, which is above most of the trajectories presented. The single trajectory that exceeds 0.5 psf is part of the high mass lunar SM debris which represents an impossible worst case scenario.

This study represents a best estimate of the expected CM and SM debris sonic boom impact to the environment. The results indicate an expected negligible impact to the environment from sonic booms produced by the CEV.

\section{Future Assessments}

Future work may include the testing of the Ops Site 1 trajectory, any abort trajectories, and any design changes that affect current trajectories. The retesting of each of the CM and SM trajectories with winds incorporated would be ideal, although this would simply result in a change in the boom carpet size and shape. Another area of consideration would be the evaluation of underwater effects.

\section{Acknowledgements}

I would like to thank Ken Plotkin for providing the PCBoom4 program and his continued support throughout my many telephone and email discussions. Thanks also goes to Dan Matz for finding Ken and to both Dan and Greg Holt for getting the program up and running with the appropriate data formatting and units. Trajectory information from Sue Stachowiak and Bini Kadwa were greatly valued as well as appreciation to Gavin Mendeck for allowing me to discuss aloud my many interpretations of the data. 

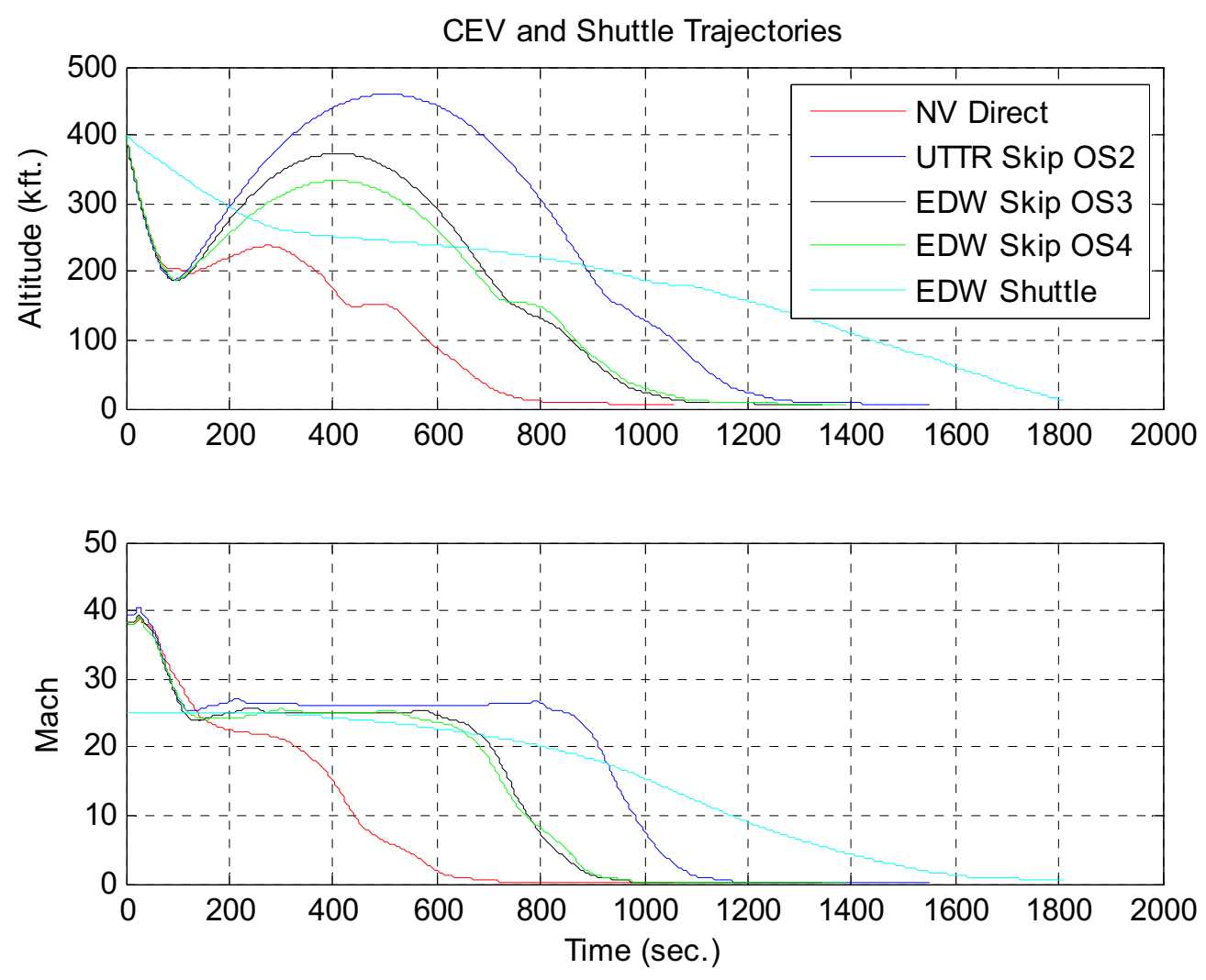

Figure 3 CEV and Shuttle Altitude and Mach Data

Peak Ground Overpressure Due to Sonic Boom, CEV Entry Carson Flats, NV - Lunar Direct

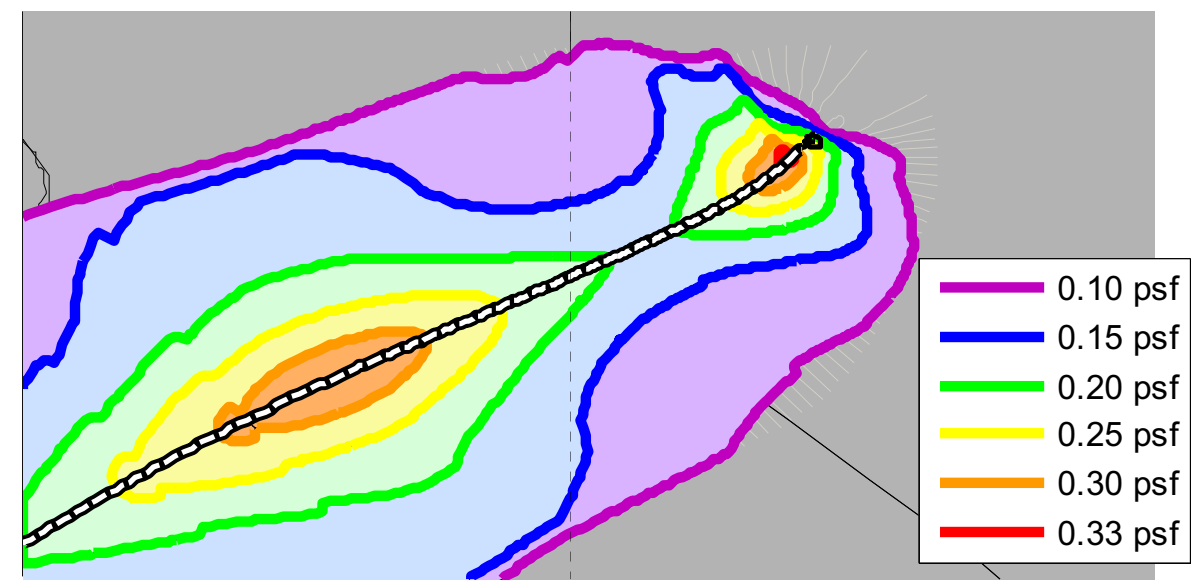

Figure 4 CEV CM Lunar Direct Entry to Carson Flats, NV Landing site is represented by a black $5 \mathrm{~nm}$ radius range circle. 
Peak Ground Overpressure Due to Sonic Boom, CEV Entry UTTR - Lunar Skip OS2

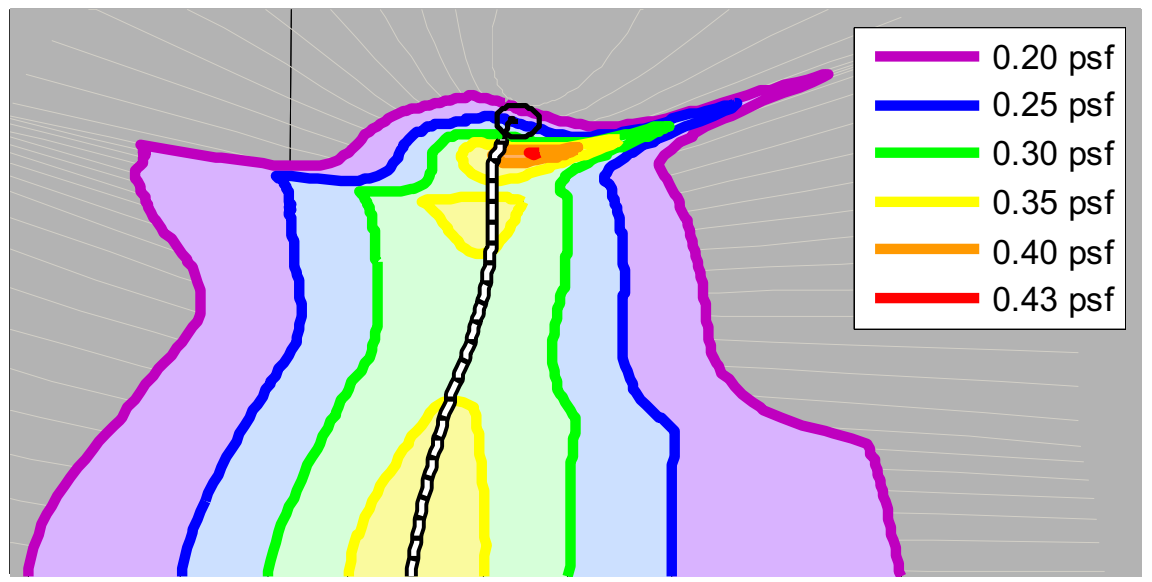

Figure 5 CEV CM Utah Test Range Lunar Skip OS2

Landing site is represented by a black $5 \mathrm{~nm}$ radius range circle.

Peak Ground Overpressure Due to Sonic Boom, CEV Entry EDW - Lunar Skip OS3

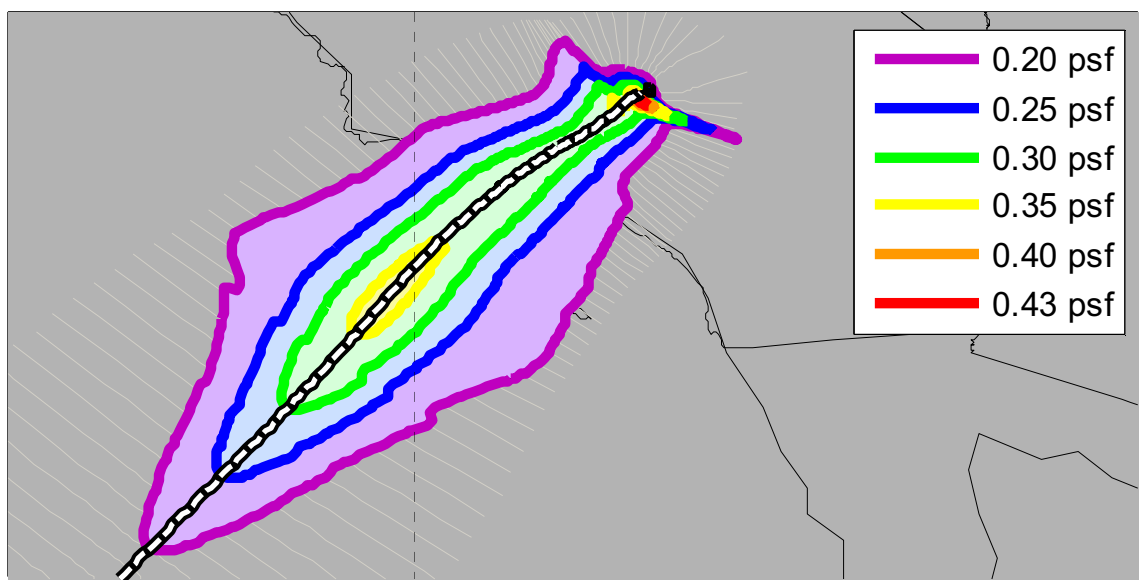

Figure 6 CEV CM Edwards AFB Lunar Skip OS3

Landing site is represented by a black $5 \mathrm{~nm}$ radius range circle. 
Peak Ground Overpressure Due to Sonic Boom, CEV Entry

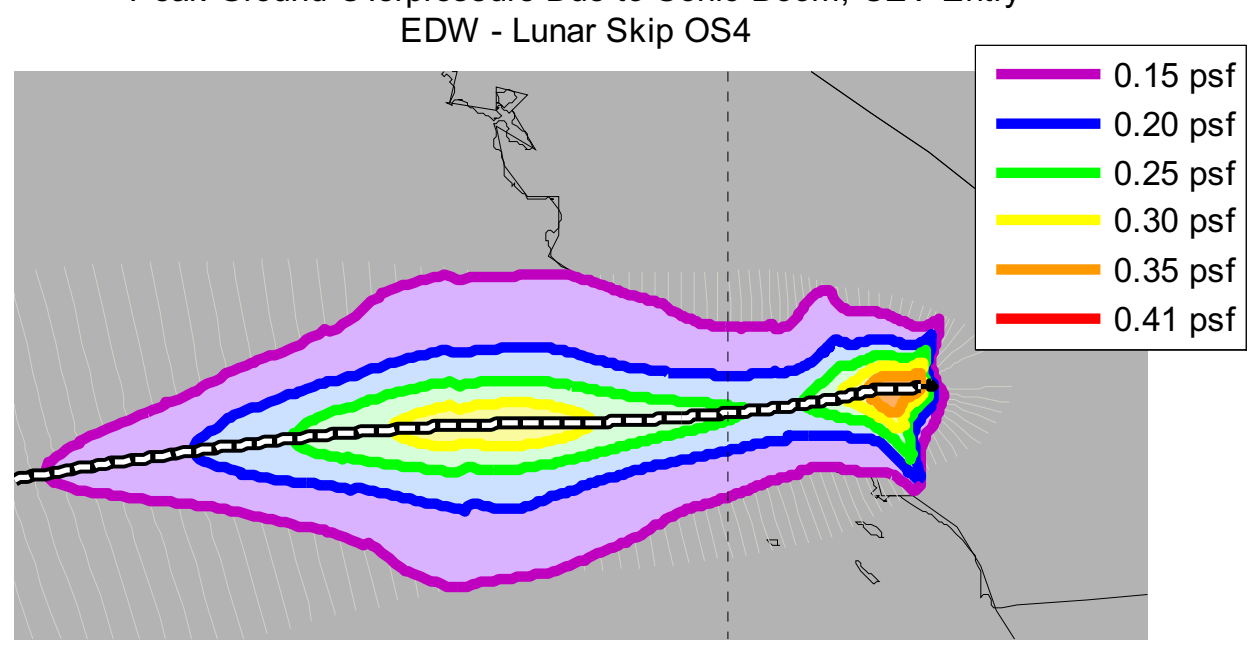

Figure 7 CEV CM Edwards AFB Lunar Skip OS4

Landing site is represented by a black $5 \mathrm{~nm}$ radius range circle. 


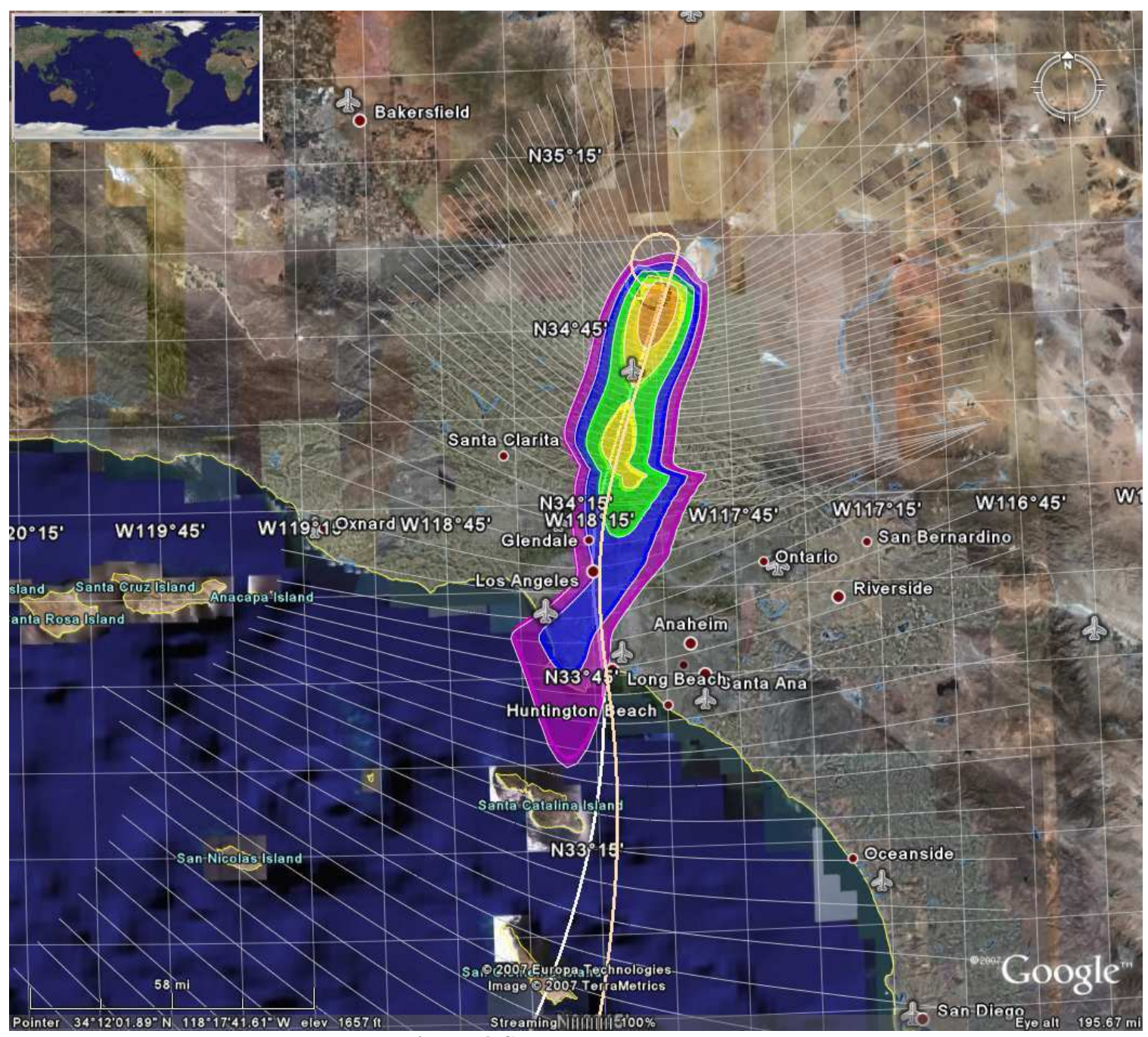

Figure 8 Shuttle Entry to EDW

Legend is 0.99 (red), 0.95 (orange), 0.90 (yellow), 0.85 (green), 0.80 (blue), 0.75 (purple) 


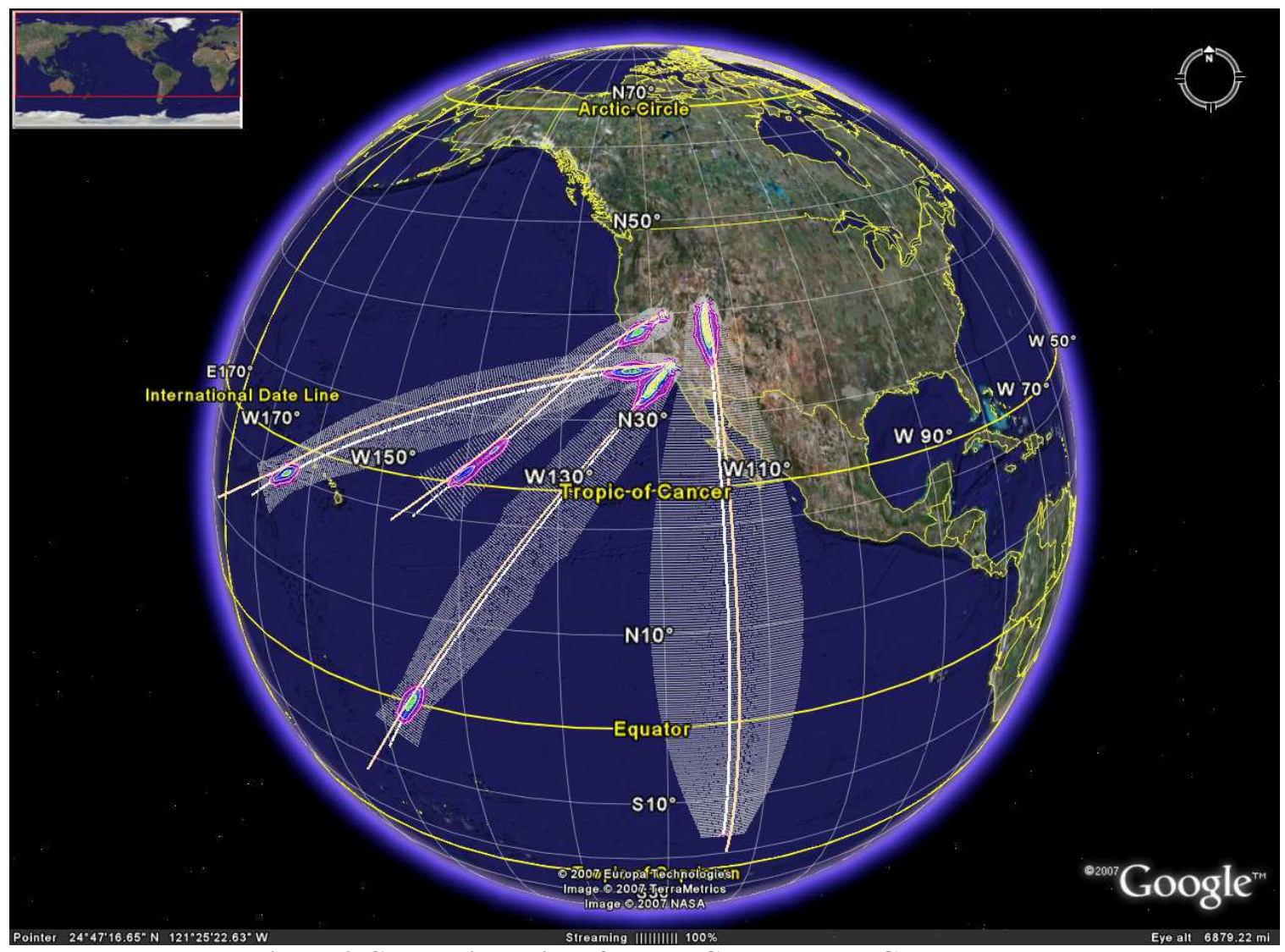

Figure 9 CM Trajectories of Lunar Cases Tested, GoogleEarth

Legend is 0.43 (red), 0.41 (orange), 0.33 (yellow), 0.30 (green), 0.25 (blue), 0.20 (purple) 


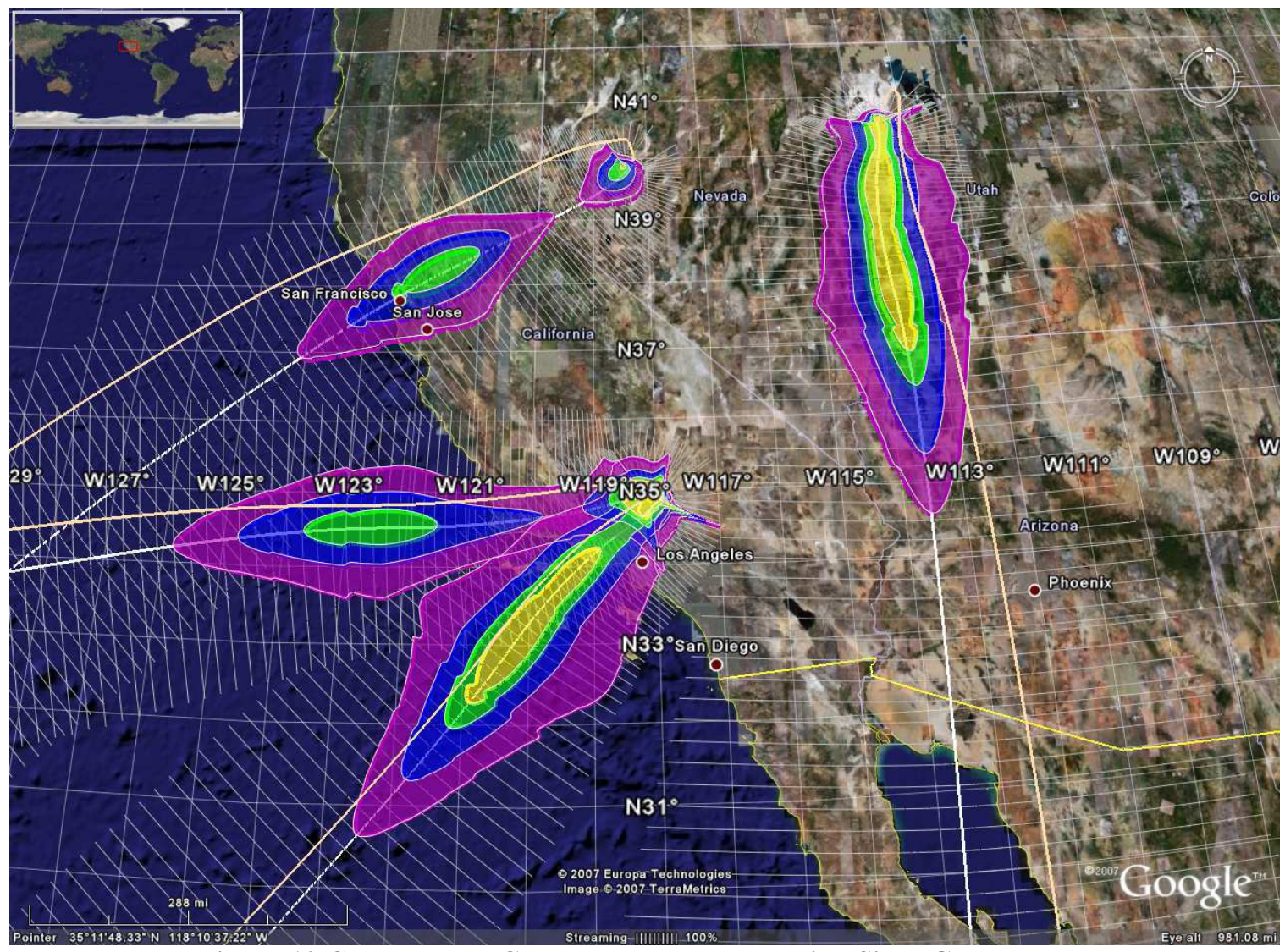

Figure 10 CM Pressure Contours at Lunar Landing Sites, GoogleEarth Legend is 0.43 (red), 0.41 (orange), 0.33 (yellow), 0.30 (green), 0.25 (blue), 0.20 (purple) 

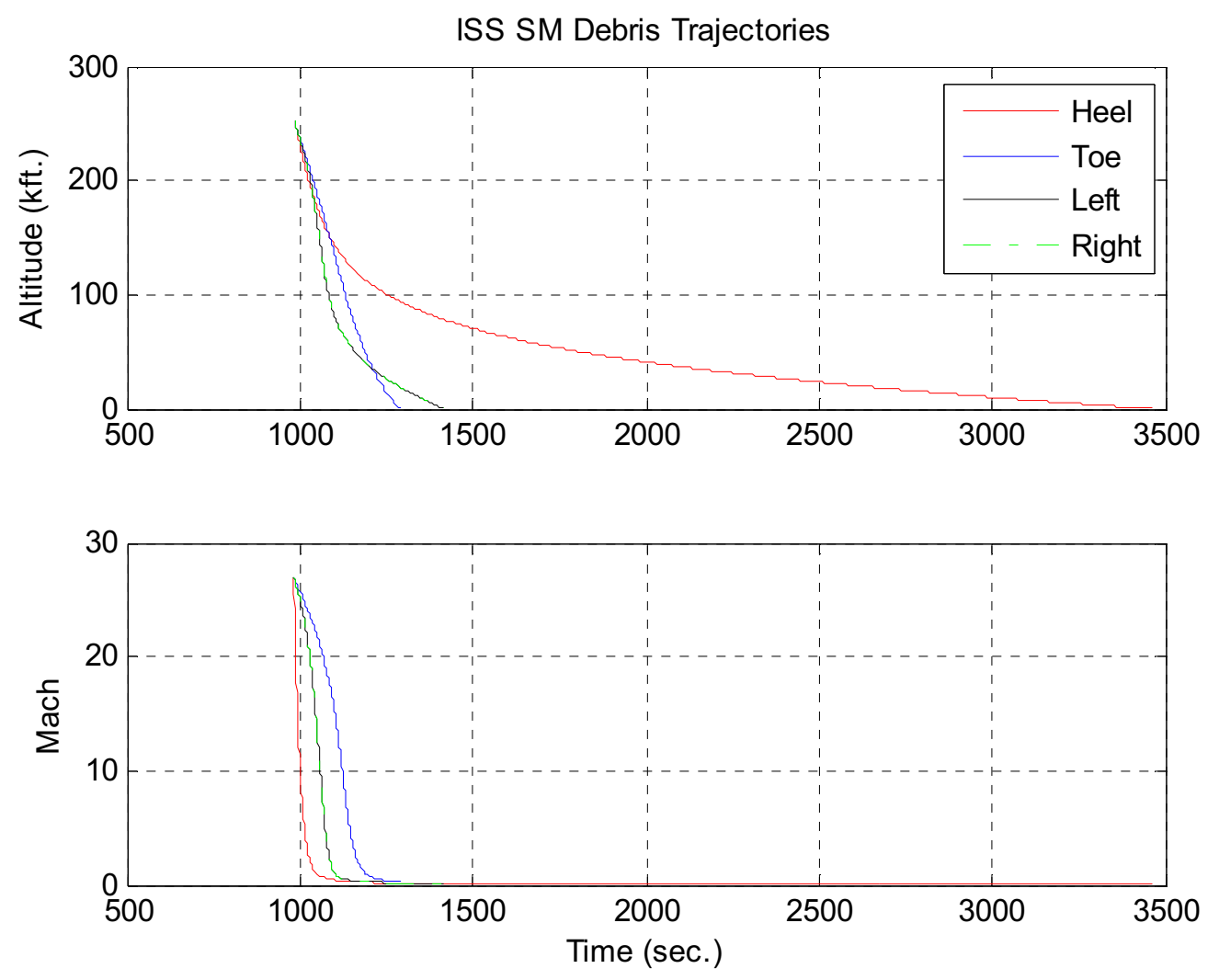

Figure 11 ISS SM Debris Altitude and Mach Data

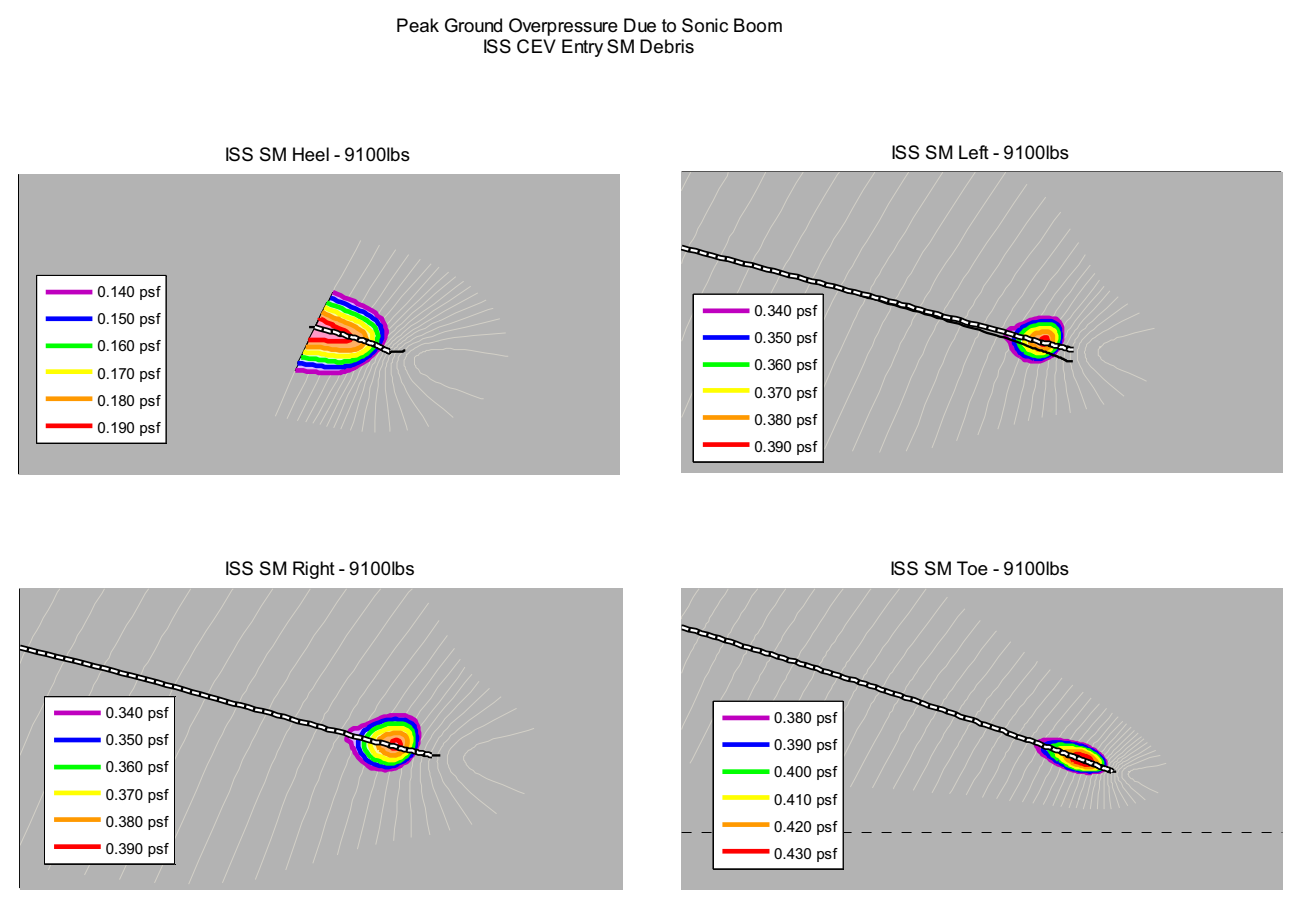

Figure 12 ISS SM Debris Pressure Contours for Debris, Mass is 9100 lbs Landing site is represented by a black $5 \mathrm{~nm}$ radius range circle. 
ISS SM Heel - 100lbs

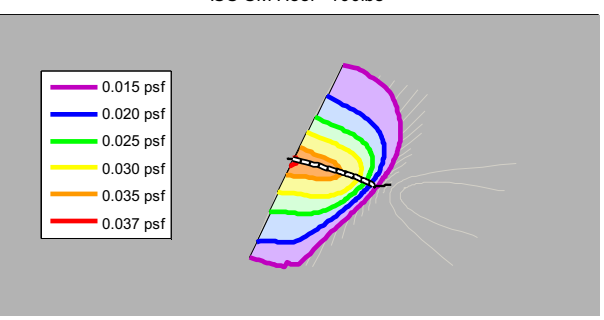

ISS SM Right - 100lbs

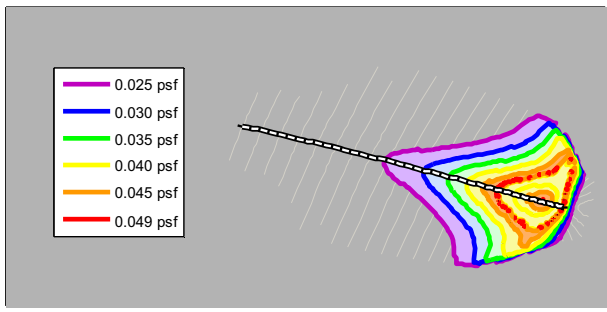

ISS SM Left - 100lbs

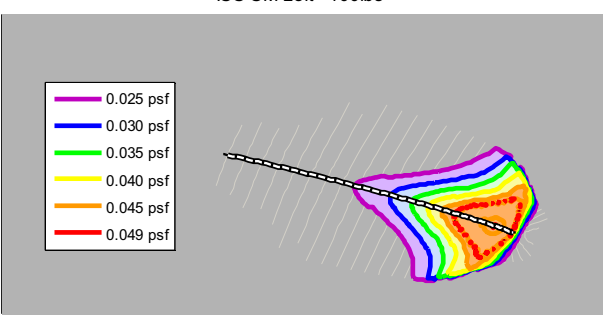

ISS SM Toe - $100 \mathrm{lbs}$

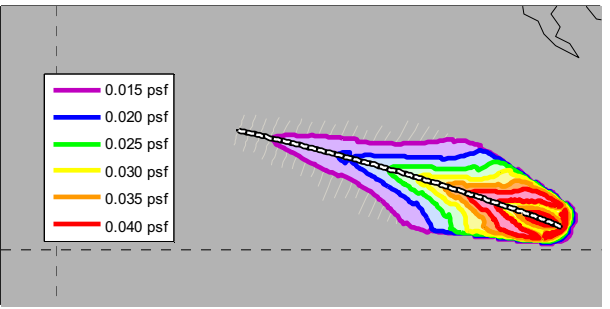

Figure 13 ISS SM Debris Pressure Contours for Debris, Mass is $100 \mathrm{lbs}$ Landing site is represented by a black $5 \mathrm{~nm}$ radius range circle. 


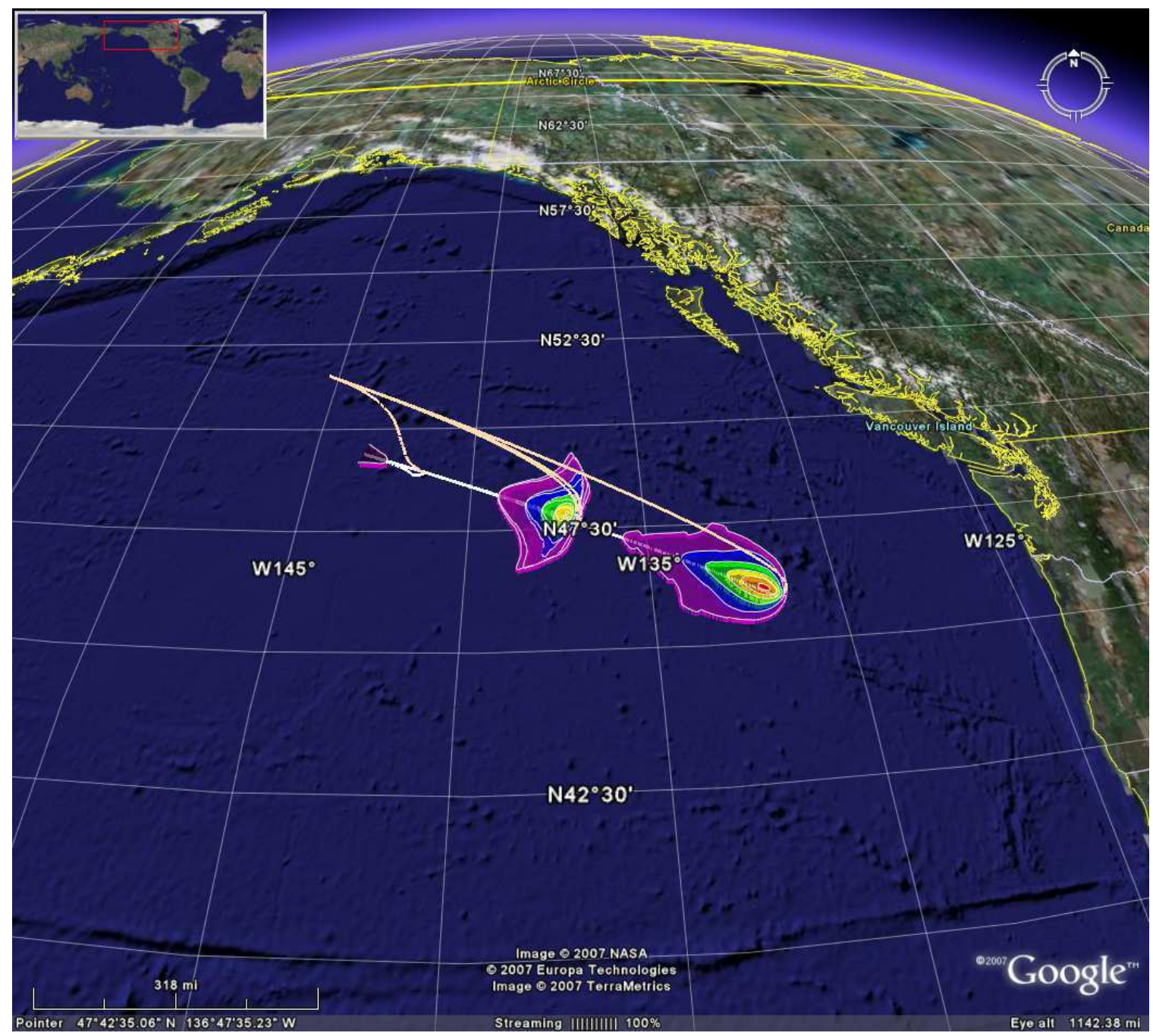

Figure 14 ISS SM Debris Pieces, Mass is $9100 \mathrm{lbs}$

Legend is 0.43 (red), 0.39 (orange), 0.35 (yellow), 0.30 (green), 0.25 (blue), 0.19 (purple) 


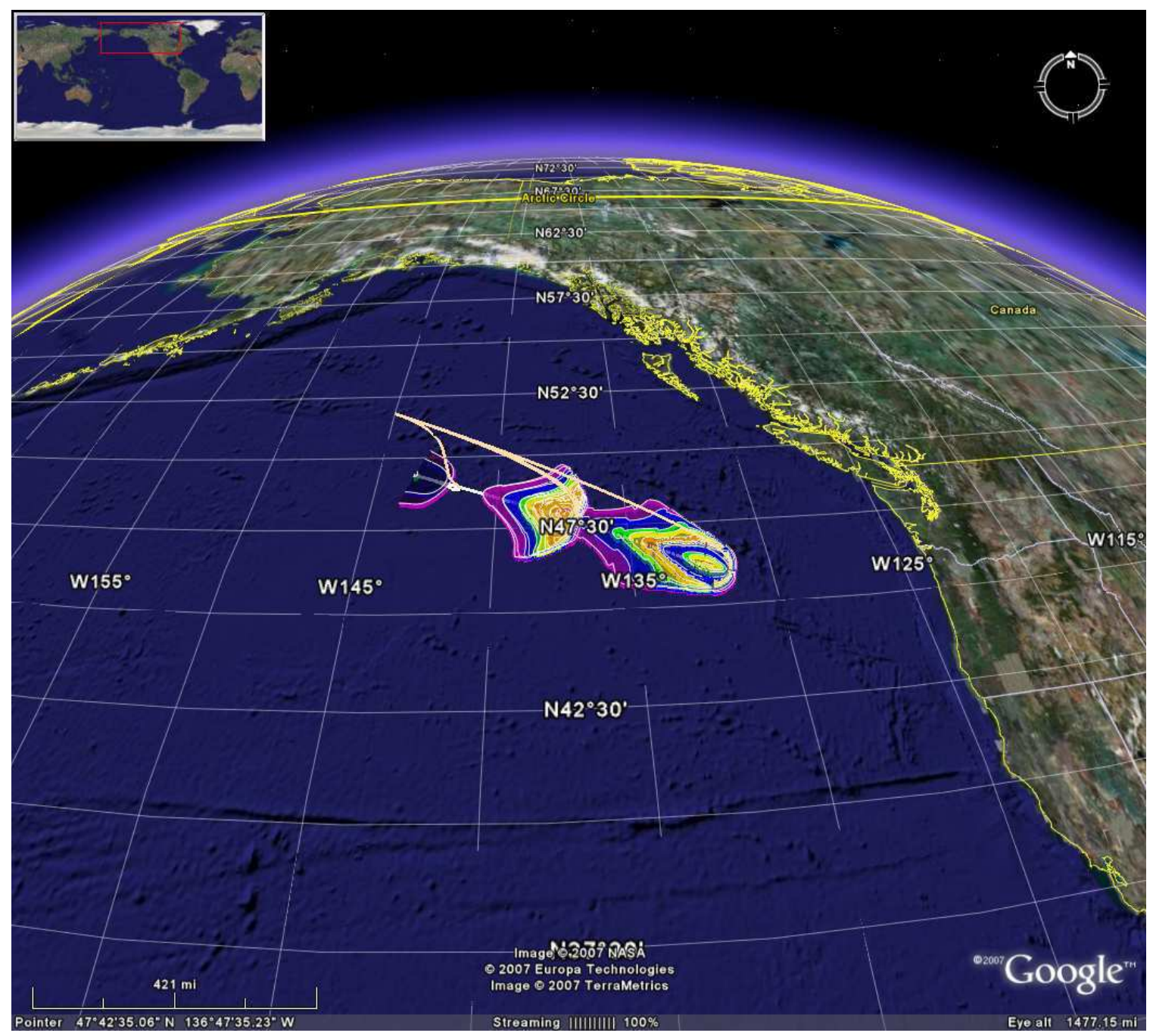

Figure 15 ISS SM Debris Pieces, Mass is $100 \mathrm{lbs}$

Legend is 0.049 (red), 0.045 (orange), 0.040 (yellow), 0.037 (green), 0.030 (blue), 0.025 (purple) 

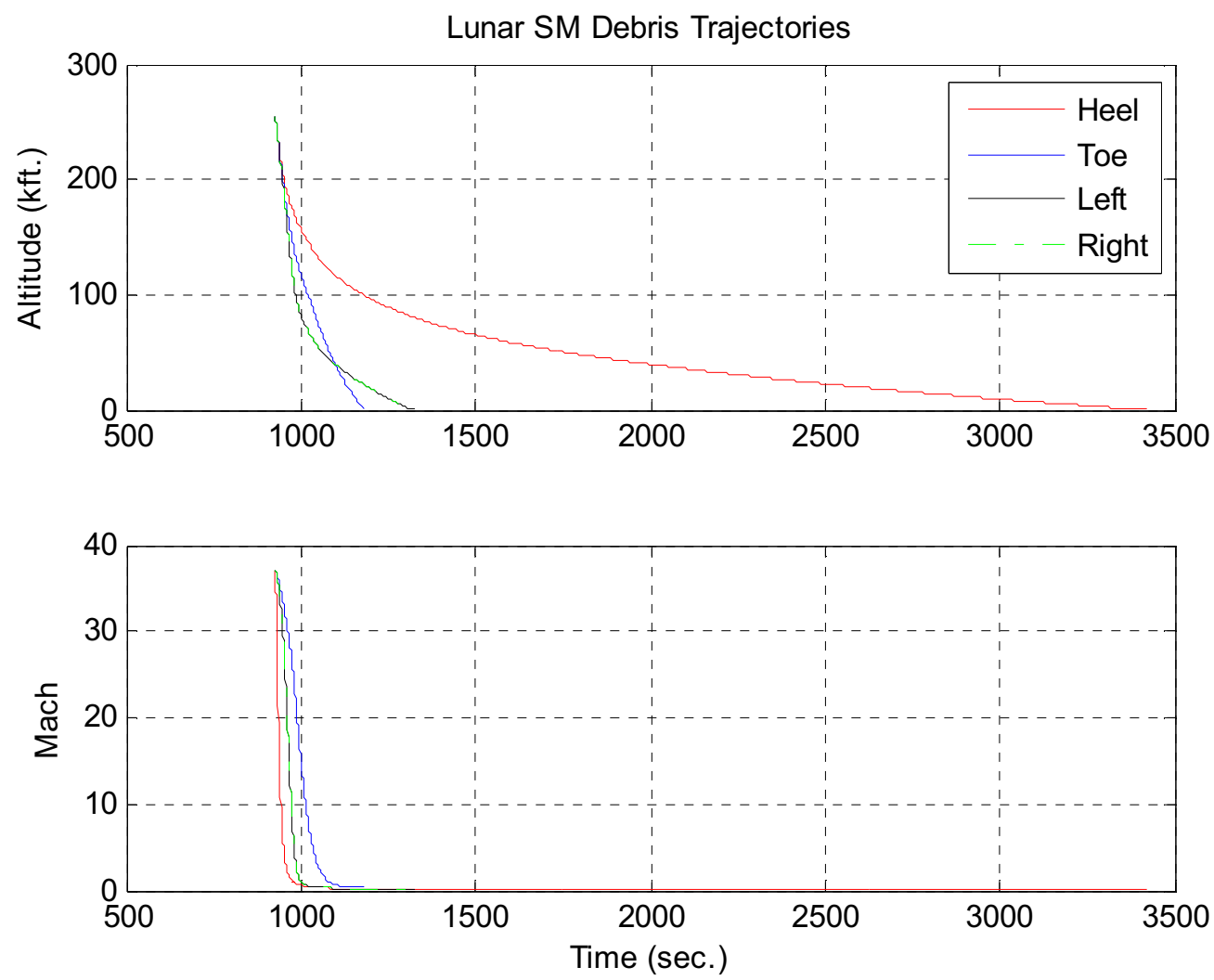

Figure 16 Lunar SM Debris Altitude and Mach Data 


\section{Lunar SM Left - 9100lbs}

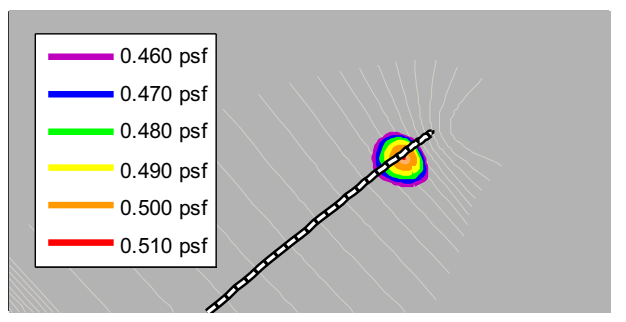

Lunar SM Heel - 9100lbs

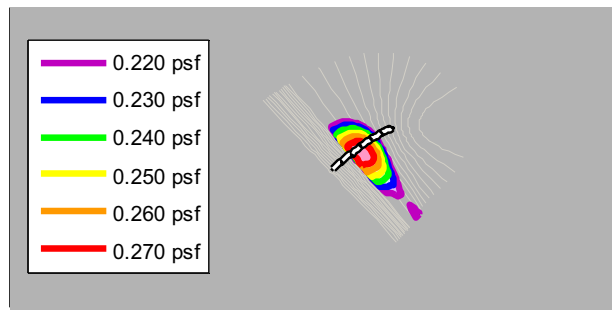

Lunar SM Toe - 9100lbs

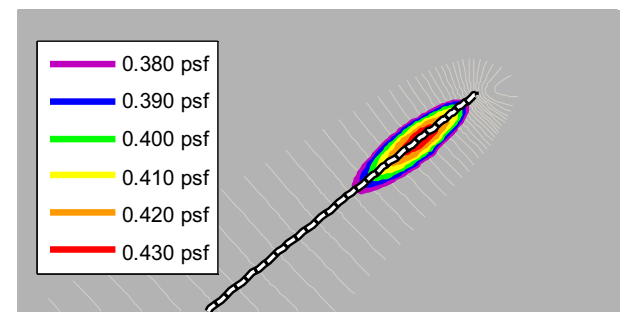

Lunar SM Right - 9100lbs

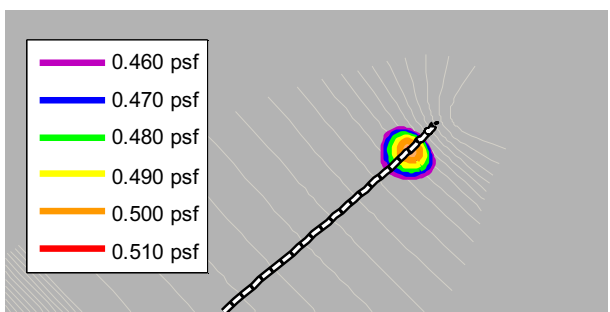

Figure 17 Lunar SM Debris Pressure Contours for Debris, Mass is 9100 lbs Landing site is represented by a black $5 \mathrm{~nm}$ radius range circle.

Peak Ground Overpressure Due to Sonic Boom Lunar CEV Entry SM Debris

Lunar SM Left - 100lbs

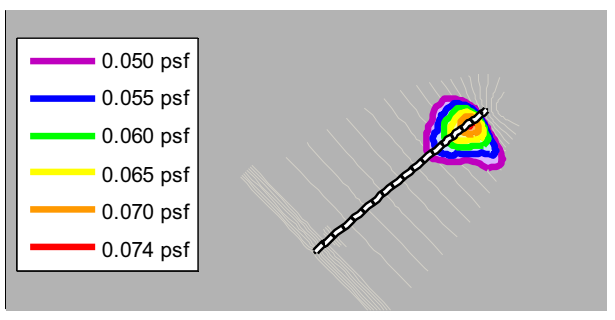

Lunar SM Heel - 100lbs

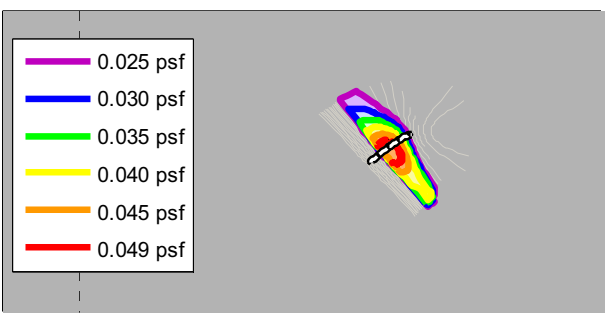

Lunar SM Toe - 100lbs

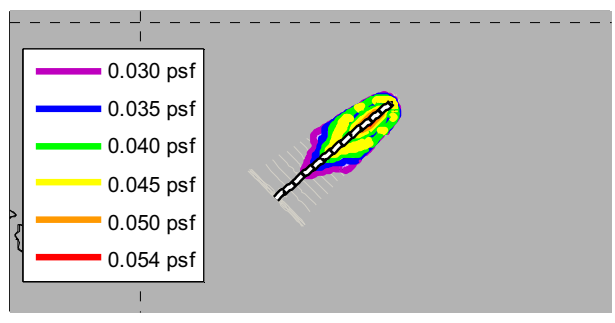

Lunar SM Right - 100lbs

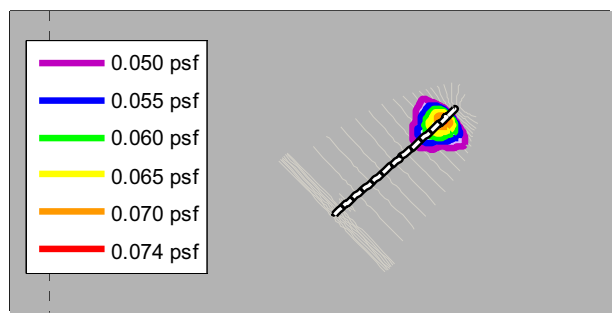

Figure 18 Lunar SM Debris Pressure Contours for Debris, Mass is 100 lbs Landing site is represented by a black $5 \mathrm{~nm}$ radius range circle. 


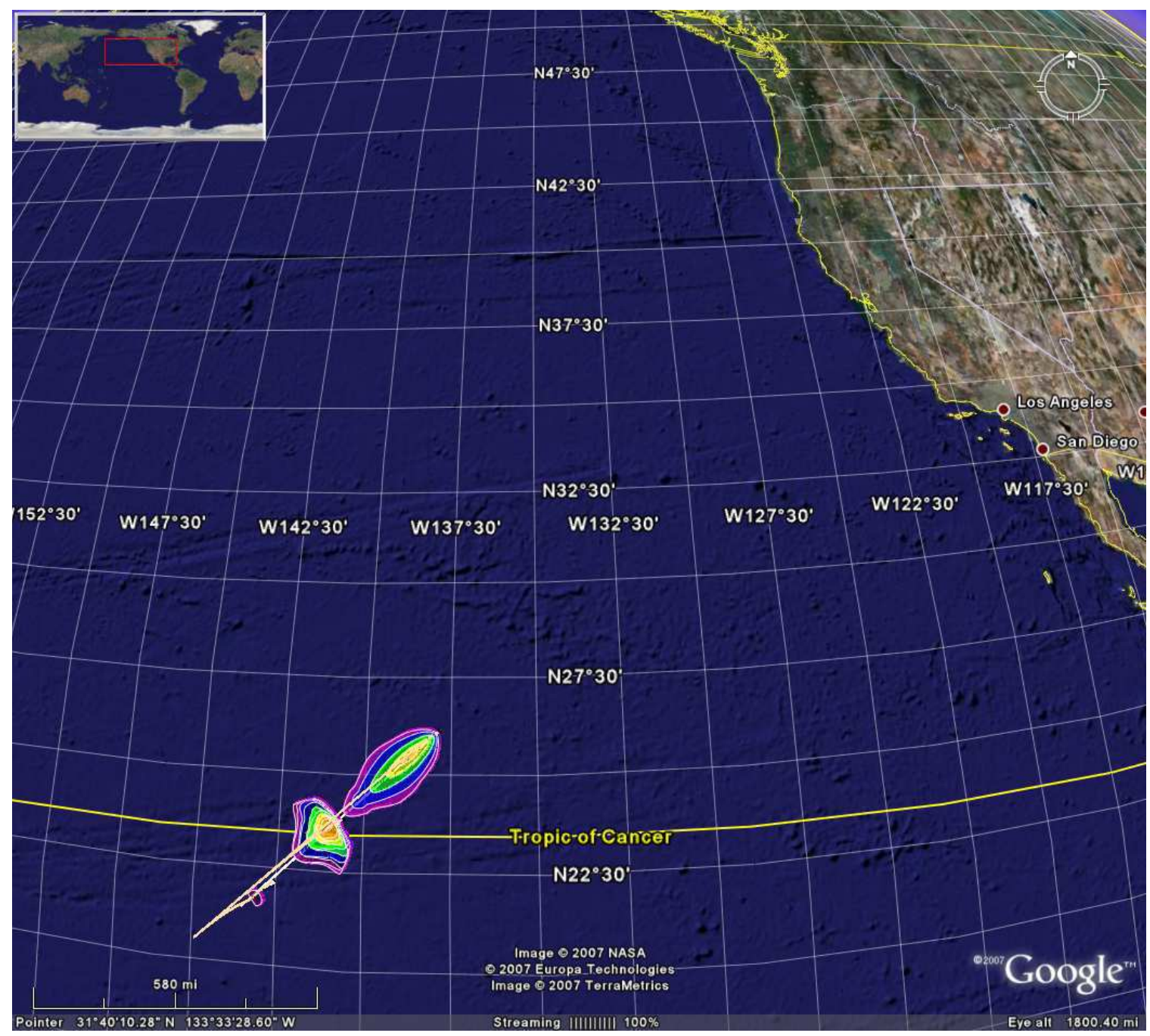

Figure 19 Lunar SM Debris Pieces, Mass is $9100 \mathrm{lbs}$

Legend is 0.51 (red), 0.43 (orange), 0.40 (yellow), 0.35 (green), 0.30 (blue), 0.27 (purple) 


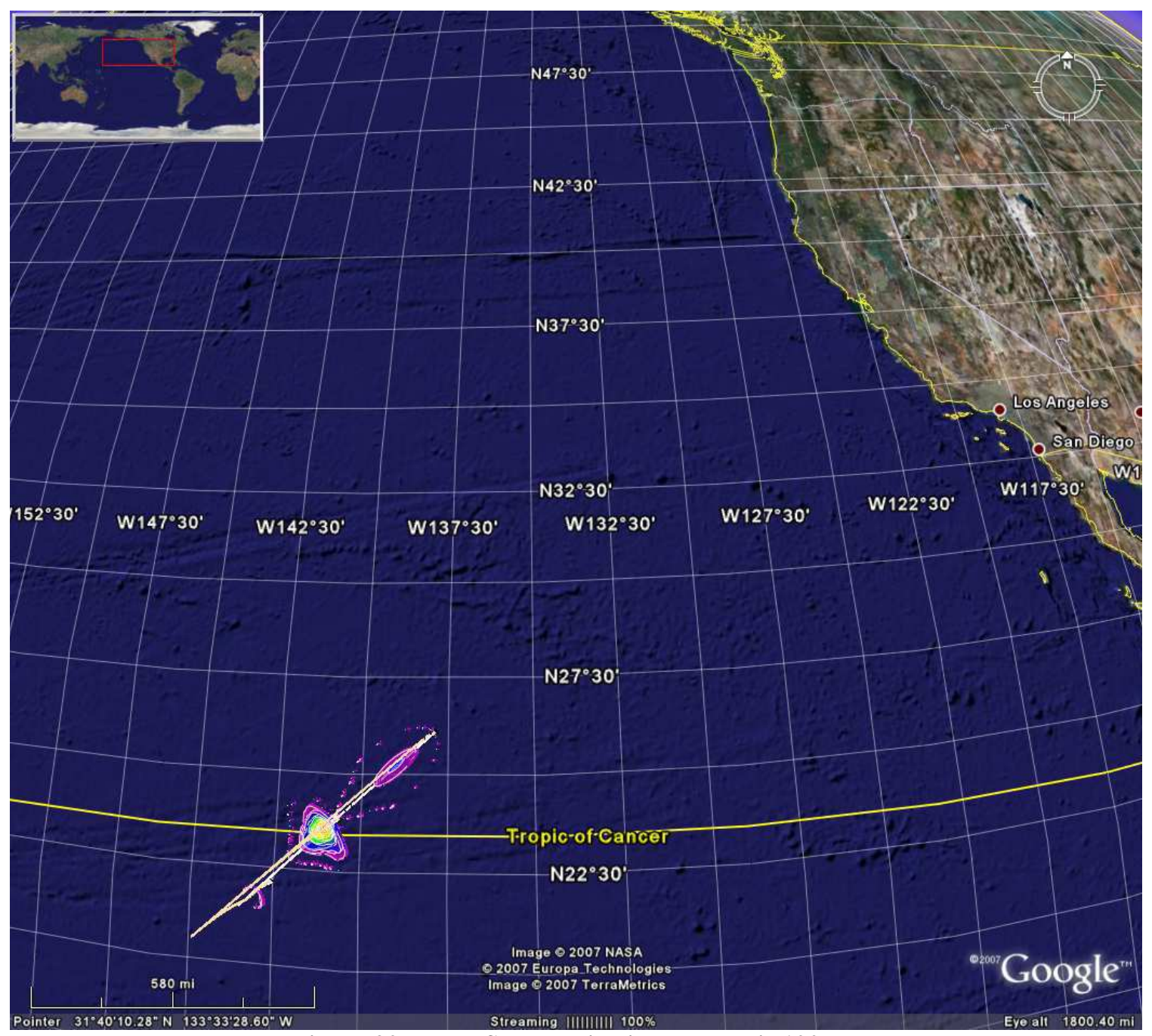

Figure 20 Lunar SM Debris Pieces, Mass is $100 \mathrm{lbs}$

Legend is 0.074 (red), 0.070 (orange), 0.065 (yellow), 0.060 (green), 0.054 (blue), 0.049 (purple) 


\section{References}

1. Lockheed Martin Space Systems Company. Crew Exploration Vehicle (CEV) Mass Properties Report. Document Number: CEV-T-045004. Denver, Colorado. August 2006.

2. National Aeronautics and Space Administration. "NASA Dryden Fact SheetSonic Booms" Edwards, California. http://www.nasa.gov/centers/dryden/news/FactSheets/FS-016-DFRC.html. November 2006.

3. National Aeronautics and Space Administration. Descent Sonic Boom Measurements For STS-26. Document Number: JSC-23579. Houston, Texas. April 1989.

4. National Aeronautics and Space Administration. Space Shuttle Missions Summary - Book 1. Houston, Texas. May 2002.

5. National Aeronautics and Space Administration. X-33 Advanced Technology Demonstrator Vehicle Program Final Environmental Impact Statement - Volume 1. Document Number: NP-1997-09-02-MSFC. Huntsville, Alabama and Kennedy Space Center, Florida. September 1997.

6. Plotkin, K., Wyle Laboratories. Telephone conversation, 12 February 2007.

7. Plotkin, K., Wyle Laboratories. "Modeling Sonic Booms in Supersonic Military Airspace," Institute for Environmental Monitoring and Research. August 2005.

8. Plotkin, K., Wyle Laboratories. PCBoom4 software

9. Plotkin, K., Franz, R. J., Haering, A. H., "Prediction and Measurement of a Weak Sonic Boom from an Entry Vehicle," Fourth Joint Meeting of the Acoustical Society of America and the Acoustical Society of Japan. Paper 2aPA3. Wyle Laboratories and NASA Dryden Flight Research Center. November 2006.

10. Plotkin, K., Wyle Laboratories. "Review of Sonic Boom Theory," American Institute of Aeronautics and Astronautics 12th Aeroacoustics Conference, April 1989, AIAA-89-1105.

11. Plotkin, K., Wyle Laboratories. "Sonic Boom," Arlington, Virginia. November 2003.

12. Plotkin, K., Wyle Laboratories. Wyle Report Computer Models for Sonic Boom Analysis: PCBoom4, CABoom, BooMap, CORBoom. Document Number: WR 02-11. Arlington, Virginia. June 2002.

13. Seebass, R., "Sonic Boom Theory," Journal of Aircraft, Vol. 6, No. 3, May-June 1969. 